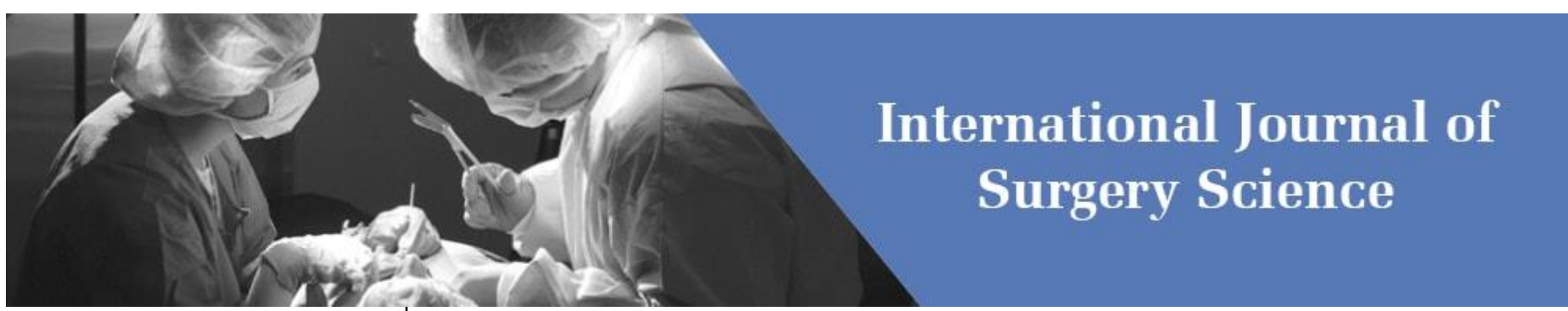

E-ISSN: 2616-3470

P-ISSN: 2616-3462

(C) Surgery Science

www.surgeryscience.com

2021; 5(4): 270-273

Received: 01-08-2021

Accepted: 03-09-2021

Dr. Vijayabhaskarreddy Sirigireddy Assistant Professor,

Department of Surgery,

SVS Medical College,

Mahabubnagar, Telangana, India

Dr. Srinivas Rao Mandalapu

Associate Professor,

Department of Surgery,

SVS Medical College,

Mahabubnagar, Telangana, India

Corresponding Author:

Dr. Srinivas Rao Mandalapu

Associate Professor,

Department of Surgery,

SVS Medical College,

Mahabubnagar, Telangana, India

\section{Clinical profile of patients with inguinal hernia at a tertiary care hospital}

\section{Dr. Vijayabhaskarreddy Sirigireddy and Dr. Srinivas Rao Mandalapu}

DOI: $\underline{\text { https://doi.org/10.33545/surgery.2021.v5.i4e.795 }}$

\section{Abstract}

Background: Around $80 \%$ of inguinal hernia cases are caused by indirect hernia. Various studies have reported that hernia accidents are more common in the elderly, who are often unaware of their diagnosis and have not sought surgical treatment.

Aim: This study was conducted to evaluate the various inguinal hernia aspects and its presentations among adult population

Materials and Methods: This study was conducted in Department of surgery in tertiary health care center during February 2018 to February 2019 in outpatient department. 50 patients were included in the study.

Results: Highest number of patients were in the age group of $>51$ years $(50 \%)$, males were $76 \%$ and females were $24 \%$ in the study, the majority of patients ( 66 percent) had an indirect hernia, while only $34 \%$ had a direct hernia, the majority of patients had a left side hernia (40\%) followed by a right side hernia (36\%) and both in 24 percent of cases, symptoms of pain when coughing, exercising was observed in majority of patients i.e. $32 \%$, followed by burning sensation (28\%), the occupation of most of the patients were farmer (54\%), followed by labourer (18\%), shopkeeper (16\%) and student (12\%).

Conclusion: The bulk of the patients in this study were in their eighties and nineties, with males accounting for the majority of the patients. The majority of the patients had an indirect hernia, with a left hernia being the most common. The majority of the patients felt pain when coughing, exercising, or leaning over.

Keywords: inguinal hernia, direct and indirect hernia

\section{Introduction}

A hernia occurs when a portion of an internal organ or tissue protrudes through a muscle. The intestines or fat from the abdomen expand through the lower abdominal wall into the inguinal, or groin, area, causing an inguinal hernia. Globally, inguinal hernias comprise $75 \%$ of all abdominal wall hernias. Inguinal hernia repair is one of the most common general surgical operations worldwide. In elderly patients, hernia accidents are more common and the patients are unaware of diagnosis and have not sorted for surgical care. The groin is where $75 \%$ of all abdominal hernias are discovered. $95 \%$ of all groin hernias are inguinal canal hernias, with the rest being femoral hernias. Men are 25 times more likely than women to develop inguinal hernias ${ }^{[1]}$. The most frequent hernia in women is the inguinal hernia. In males, the lifetime risk of acquiring a groin hernia is around $15 \%$, while in females, the risk is less than $5 \%$. There is a link between age and the presence of a hernia. At the extremes of age, hernia problems such as imprisonment and strangling are more likely ${ }^{[2]}$. Incidence of indirect inguinal hernia is only around 66 percent. Almost all hernias in women and children are caused by an indirect hernia. Oblique indirect hernia is another name for it. The hernia enters through the internal inguinal ring, which is lateral to the inferior epigastric artery, and descends obliquely downwards and medially before obliquely reducing ${ }^{[3]}$.

In the first decade, it is more prevalent on the right side, but in the second decade, it is equally common on both sides. It comes in two varieties: congenital and acquired. When the testis reaches the scrotum, the funicular process of the peritoneum is normally obliterated. Tunica vaginalis is the scrotal residue of this procedure. The entire process is patent in the case of congenital hernia. As a result, the bottom of the scrotum is reached by indirect hernia. Hernia terminates at this point if the funicular process is only patent up to the top of the testis ${ }^{[4]}$. Congenital funicular hernia is the medical term for this condition. It doesn't intrude into a sac that has already been created. It takes time to appear and progress. 
Direct hernia is a type of hernia that occurs when the stomach is A straight inguinal hernia's sac protrudes outward and forward, lying between the internal inguinal ring and the inferior epigastric veins. It's due to a weakening in the inguinal canal's posterior wall that has developed over time.

This type of hernia occurs more frequently in those over the age of 40. It is normally incomplete, but it may descend into the scrotum in long-term situations. It is possible to have bilateral. Among the signs and symptoms of an inguinal hernia are: A bulge on either side of your pubic bone that becomes more noticeable when you're standing up, especially if you cough or strain. At the protrusion, there is a burning or hurting sensation. Groin pain or discomfort, particularly when bending over, coughing, or lifting. Feeling weighty or dragging in your groin. In your groin, there is a feeling of weakness or pressure ${ }^{[5]}$. When the projecting intestine lowers into the scrotum, it can cause pain and swelling around the testicles. Inguinal hernias can occur for a variety of reasons. Others could happen as a result of an increase in abdominal pressure, straining during bowel movements or urine, a pre-existing weak area in the abdominal wall, arduous exercise, pregnancy and coughing or sneezing on a regular basis. The purpose of this study was to determine the prevalence, age and gender disparities, and risk factors related with inguinal hernias. In addition, the indications and symptoms, as well as the type of the presentation, were investigated. Muscle weakness (previous appendectomy or other abdominal operations), physical stress, increased intraabdominal pressure (chronic constipation and prostatism), smoking, ageing, pelvic fractures and trauma, connective tissue disease, and systemic illnesses were all found to be risk factors for inguinal hernia in male populations. Obesity, pregnancy, and operational procedures have all been identified as risk factors for the development of inguinal hernia in women. To the best of our knowledge and based on a thorough examination of the literature, none of these risk factors have been studied together. This study was conducted to evaluate the various inguinal hernia aspects and its presentations among adult population.

\section{Materials and Methods}

This study was conducted in Department of surgery in tertiary health care center during February 2018 to February 2019 in outpatient department. Those who were diagnosed with inguinal hernia were included in the study. Patients with malignancies and those who came for post-operative problems were not included in the study. 50 patients were included in the study.

Method of data collection these patients presented with either swelling in the groin/ pain in the groin area of varying duration. Patients with these symptoms were admitted to surgical ward with the diagnosis of direct or indirect uncomplicated inguinal hernia. A detailed relevant clinical history was done as the proforma approved by the guide. After routine investigations, Patients were informed about the various techniques and advantages of the PHS mesh. In those patients who agreed, consent was taken and patients were prepared for surgery. Patients were subjected to Prolene Hernia system repair. All patients were given preoperative antibiotic prophylaxis with Injection Ceftriaxone $1 \mathrm{gm}$. Spinal anaesthesia was administered. Statistical Analysis: The Statistical software namely Graphpad was used for the analysis of the data and Microsoft word and Excel have been used to generate graphs, tables etc.

\section{Result}

Table 1: Distribution based on age of patients

\begin{tabular}{|c|c|c|}
\hline Age & Number & Percentage \\
\hline $1-10$ & 0 & 0 \\
\hline $11-21$ & 2 & 4 \\
\hline $22-31$ & 5 & 10 \\
\hline $32-41$ & 6 & 12 \\
\hline $42-51$ & 12 & 24 \\
\hline$>51$ & 25 & 50 \\
\hline
\end{tabular}

Table 1 shows that the highest number of patients were in the age group of $>51$ years $(50 \%)$ and least number of patients were in the age group of 11-21 years (4\%).

Table 2: Distribution based on gender

\begin{tabular}{|c|c|c|}
\hline Sex & Number & Percentage \\
\hline Male & 38 & $76 \%$ \\
\hline Female & 12 & $24 \%$ \\
\hline
\end{tabular}

Table 2 shows that males were $76 \%$ and females were $24 \%$ in the study.

Table 3: Distribution based on type of hernia

\begin{tabular}{|c|c|c|}
\hline Type & Number & Percentage \\
\hline Direct & 17 & 34 \\
\hline Indirect & 33 & 66 \\
\hline
\end{tabular}

Table 3 shows that majority of patients had indirect hernia $(66 \%)$ and direct hernia was observed in $34 \%$ of patients.

Table 4: Distribution based on laterality

\begin{tabular}{|c|c|c|}
\hline Type & Number & Percentage \\
\hline Right & 18 & 36 \\
\hline Left & 20 & 40 \\
\hline Both & 12 & 24 \\
\hline
\end{tabular}

Table 4 shows that majority of patients had left side hernia which constituted to $40 \%$, followed by right side hernia $(36 \%)$ and both was observed in $24 \%$ of patients.

Table 5: Distribution based on symptoms

\begin{tabular}{|c|c|c|}
\hline Symptoms & Number & Percentage \\
\hline Pain when coughing, Exercising, leaning over & 16 & 32 \\
\hline Burning sensation & 14 & 28 \\
\hline Sharp pain & 8 & 16 \\
\hline Heavy sensation & 7 & 14 \\
\hline Scrotum swelling in men & 5 & 10 \\
\hline
\end{tabular}

Table 5 shows that symptoms of pain when coughing, exercising was observed in majority of patients i.e. 32\%, followed by burning sensation (28\%), sharp pain (16\%), heavy sensation $(14 \%)$ and scrotum swelling in men $(10 \%)$.

Table 6: Distribution based on occupational status

\begin{tabular}{|c|c|c|}
\hline Occupational Status & Number & Percentage \\
\hline Farmer & 27 & 54 \\
\hline Shopkeeper & 8 & 16 \\
\hline Labourer & 9 & 18 \\
\hline Student & 6 & 12 \\
\hline
\end{tabular}


Table 6 shows that the occupation of most of the patients were farmer $(54 \%)$, followed by labourer $(18 \%)$, shopkeeper $(16 \%)$ and student $(12 \%)$.

Table 7: Associated comorbidities in present study

\begin{tabular}{|c|c|c|}
\hline Associated comorbidities & Number of cases & Percentages \\
\hline Hypertension & 12 & 24 \\
\hline Diabetes mellitus & 11 & 22 \\
\hline Benign prostatic hyperplasia & 7 & 14 \\
\hline COPD & 6 & 12 \\
\hline Others & 4 & 8 \\
\hline
\end{tabular}

Most common associated co- morbidity was HTN, present in 12 cases accounting for $24 \%$ followed by Diabetes mellitus of $22 \%$

\section{Discussion}

In present study, highest number of patients were in the age group of $>51$ years $(50 \%)$ and least number of patients were in the age group of 11-21 years (4\%). In Sanjay Gawale et al. ${ }^{[6]}$ study, similar results were observed. The majority of the patients were between the ages of 50 and 54.76 percent, with 40-5023.80 percent, $30-40-11.90$ percent, $20-30-7.14$ percent, and 1020- 2.38 percent following. Faraj et al. ${ }^{[7]}$ found that the average age of the population $(\mathrm{n}=187$ ) was 62.2 years (range 28-92). According to a study by Indranil Basu et al. ${ }^{[8]}$, the greatest incidence of inguinal hernia occurred between the ages of 42 and 57 years. In adolescent age groups, it is far less common. Many research, such as this one, refuted this claim. However, several investigations have revealed that the age distribution is bimodal, with peaks in early childhood and old age. In present study, males were $76 \%$ and females were $24 \%$ in the study. Similar results were also observed in Sanjay Gawale et al. ${ }^{\text {[6] }}$ study, in this study, observed Males made for 76.19 percent of the patients, with females accounting for 23.81 percent. Male to female ratio was 15:1 (175:12) in Faraj et al. 7 study. Men had a 15 to 27 percent lifetime chance of developing inguinal hernia, whereas women had a 3 percent lifetime risk, despite the fact that the male to female ratio in the US population is 5:18 in studies conducted by Gulzar M.R. et al. ${ }^{[9]}$, Zimmermann L.M. et al. ${ }^{[10]}$ and Fitzgibbons et al. ${ }^{[11]}$. In present study, hernias of left inguinal were more common compared to hernias of right inguinal. In Mukesh Sangwan et al. ${ }^{[12]}$ study, the right versus left inguinal hernia was 1.45:1. In Kulah B et al. ${ }^{[13]}$ study, $63 \%$ had hernia on their right side and $37 \%$ had hernia on their left side which shows that it is contrast result when compared to the present study. In present study, symptoms of pain when coughing, exercising was observed in majority of patients i.e. $32 \%$, followed by burning sensation (28\%), sharp pain (16\%), heavy sensation (14\%) and scrotum swelling in men $(10 \%)$. Similar results were also observed in Sanjay Gawale ${ }^{6}$ et al. study. Constance $\mathrm{E}^{14}$ et al. conducted a study in which older age, obesity, greater height, chronic cough, rural residence were associated with inguinal hernia. Many other research studies such as Lau $\mathrm{H}^{15}$ et al. and Junge $\mathrm{K}$ et al. ${ }^{[16]}$, have found that family history is a major predictor of inguinal hernia formation and recurrent hernia. Chronic cough, chronic constipation, chronic diabetes, and prostate enlargement were some of the other risk factors. In Mukesh Sangwan et al. ${ }^{[12]}$ study, prostatism symptoms were present in around $16 \%$ of cases, while hypertension and diabetes symptoms were present in about $11 \%$ and $5 \%$ of cases, respectively. Hair et al. ${ }^{[17]}$ study found that 66 percent of patients experienced pain in addition to edoema. In Sachin HG et al. ${ }^{[18]}$ study, more than half of the patients had a right-sided hernia $(51.1 \%)$, followed by a left- sided hernia (49.1\%). (40.0 percent). Bilateral hernias accounted for $8.9 \%$ of all hernias. Swelling was the most prevalent presenting symptom, accounting for 66.7 percent of cases, followed by swelling with pain accounting for 33.3 percent. Shivakumar et al. ${ }^{[19]}$ study showed similar results to present study and it was observed that $70 \%$ were indirect, $30 \%$ were direct, with 63.33 percent being on the right side and 36.66 percent on the left. In the present study, the occupation of most of the patients were farmer (54\%), followed by labourer $(18 \%)$, shopkeeper $(16 \%)$ and student $(12 \%)$. Similar results were also observed in Sachin HG et al. ${ }^{[18]}$ study. Workers with moderate to high activity levels (farmers, labourers) accounted for 62.3 percent of all cases.

\section{Conclusion}

This study concluded that the majority of the patients were in their eighties and nineties; Males made up the majority of the patients. The majority of the patients had an indirect hernia; the majority of the patients had a left hernia. When coughing, exercising, or leaning over, the majority of the patients experienced pain. Sensations of burning above the hernial site; the hernial location is in excruciating discomfort. In the groin, there is a heavy or full sensation.

\section{References}

1. Rao SS, Singh P, Gupta D, Narang R. Clinicoepidemiologic profile of inguinal hernia in rural medical college in central India. J Mahatma Gandhi Inst Med Sci 2016;21:116-21.

2. Repair of Inguinal Hernia. Hernia. Philadelphia: J.B. Lippincott Company, 1995.

3. Williams Normans Baileys S. \& Love`s Short Practice of Surgery, Ch 57, $26^{\text {th }}$ Edition, 968.

4. Donald EF, Richards AT, Cunningham Hernia J. 5th ed Part I-IV. In; Nyhus and Condon's Hernia, Fitzgibberns RJ, Greenberg AG, eds. Philadelphia: Lippincots Williams and Wilkins Desktop Division, A Wolters Kluwer company, 2002, 3-225.

5. John Jenkins T, Patrick O’Dwyer J. Inguinal hernias. British Medical Journal. BMJ. 336(7638), 269-272.

6. Sanjay Gawale, Naresh Rathod. A clinical profile and prevalence of the inguinal hernia at the tertiary health care center; International Journal of Recent Trends in Science and Technology 2016;9(2):263-265.

7. Faraj D, Ruurda JP, Olsman JG, Van Geffen HJ. Five-year results of inguinal hernia treatment with the Prolene Hernia System in a regional training hospital. Hernia 2010;14(2):155-8.

8. Indranil Basu, Sudhangshou SekharBhoj, Ananda Kumar Mukhopathyay. Retrospective Study on Prevalence of Primary and Recurrent Inguinal Hernia and its Repairs in Patients Admitted to a Tertiary Care Hospital. Indian Medical Gazette, 2013, 203-213.

9. Gulzar MR, Iqbal J, Ulhaq MI, Afzal M. Darning vs Bassini repair for inguinal hernia-A pro-spective comparative study. Professional Medical Journal 2007;14:128-133.

10. Zimmermann LM, Amson BJ. Anatomy and surgery of hernias, 2nd Edition, Willium and Wilkins, Baltimore, 1967.

11. Fitzgibbons RJ, Filipi CJ, Thomas HQ. Inguinal hernia. In: Brunicardi FC, Andersen DK, Bi-lliar TR, Dunn DL, Hunter JG, Pollock RE, Eds., Schwartz's Principles of Surgery, 8th Edition, McGraw- Hill, New York, 2005.

12. Mukesh Sangwan, Vijayata Sangwan, Mahender Garg, Parveen Mahendirutta, Uma Garg. Abdominal wall hernia 
in a rural population in India-Is spectrum changing? Open journal of epidemiology 2013;3:135-138.

13. Kulah B, Kulacoglu IH, Oruc MT, Duzgun AP, Moran M, Ozmen MM, et al. Presentation and outcome of incarcerated external hernias in adults. Am J Surg 2001;181(2):101-4.

14. Constance E. Ruhl1, James Everhart E. Risk Factors for Inguinal Hernia among Adults in the US Population. American journal of Epidemiology. Am $\mathrm{J}$ Epidemiol 2007;165(10):1154-1161.

15. Lau H, Fang C, Yuen WK, Patil NG. Risk factors for inguinal hernia in adult males: A case control study. Surgery 2007;141:262-266.

16. Junge K, Rosch R, Klinge U, Schwab R, Peiper C, Binnebosel $\mathrm{M}$, et al. Risk factors related to recurrence in inguinal hernia repair: a retrospective analysis. Hernia 2006;10:309-315.

17. Hair A, Paterson C, Wright D, Baxter JN, O’Dwyer PJ. What effect does the duration of an inguinal hernia have on patient symptoms? J Am Coll Surg 2001;193(2):125-9.

18. Dr Sachin HG, Dr Konappa V, Dr Karunakar GK, Dr Chandrashekar S. Clinical Profile of Patients with Inguinal Hernia Admitted at Tertiary Care Hospital; European Journal of Molecular \& Clinical Medicine, 2021, 08(04). ISSN 2515-8260.

19. Shivakumar, Chandrashekar Naik G. Clinical profile of patients with inguinal hernia at a tertiary care hospital. Med Pulse International Journal of Surgery 2017;4(1):17-19. 